\title{
ANÁLISE OPERACIONAL DE UM SISTEMA FOTOVOLTAICO DE BOMBEAMENTO DE ÁGUA ${ }^{1}$
}

\author{
EVANDRO M. KOLLING ${ }^{2}$, SAMUEL N. M. DE SOUZA ${ }^{3}$, \\ REINALDO P. RICIERI ${ }^{3}$, SILVIO C. SAMPAIO ${ }^{3}$, RIVANILDO DALLACORT ${ }^{4}$
}

RESUMO: O bombeamento de água é uma das atividades mais difundidas quanto ao emprego da energia solar fotovoltaica. Porém, apesar de se apresentar como alternativa interessante, o alto custo, a baixa eficiência dos sistemas e os projetos inadequados restringem sua aplicação. O uso racional, baseado na utilização mais eficiente de seus equipamentos, está vinculado ao conhecimento do comportamento operacional desses sistemas. No presente trabalho, teve-se o objetivo de avaliar o comportamento de um sistema fotovoltaico de bombeamento de água diretamente acoplado, sob diferentes condições de irradiância solar, por meio da montagem de uma bancada de testes, submetendo-o a diferentes alturas manométricas e determinando-se a vazão fornecida. A análise dos resultados permitiu estabelecer um modelo de regressão para estimativa de vazão do sistema em função da irradiância e altura manométrica. Concluiu-se que a potência gerada pelo painel e a vazão fornecida pela motobomba estão diretamente relacionadas à irradiância solar e à altura manométrica e influenciam na eficiência do sistema. A máxima eficiência do painel foi de $8 \%$, 39\% para a motobomba e $2,3 \%$ na interação dos componentes.

PALAVRAS-CHAVE: irradiância solar, carga de bombeamento, vazão do sistema.

\section{OPERATIONAL ANALYSIS OF A PHOTOVOLTAIC WATER PUMPING (PV) SYSTEM}

SUMMARY: The pumping of water is one of the activities most diffused to the employment of the photovoltaic solar energy, in spite of coming as an interesting alternative, the high cost and it lowers efficiency of the systems with the inadequate projects, still restricts its application. The rational use, based on the most efficient use of its equipments is linked to the knowledge of the operational behavior of these systems. The present work objectified to evaluate the operational behavior of a photovoltaic water pumping directly coupled operating in different conditions of solar irradiance, by means of the assembly of supported tests, submitting to different manometer elevation and determining the supplied rate flux of water. The analysis of the results allowed to determine a regression model for flux of water estimation as function of irradiance and manometer elevation. Was concluded that the power generated by the array and the rate flux supplied by the motor-pump is directly related to the solar irradiance. The maximum efficiency of the array was of $8 \%, 39 \%$ for the motor-pump and, $2.3 \%$ in the interaction of the components in the system.

KEYWORDS: solar irradiation, pumping head, flow of system.

\footnotetext{
${ }^{1}$ Extraído da dissertação de Mestrado do primeiro autor.

${ }^{2}$ Eng ${ }^{\circ}$ Agrícola, M.Sc., COAMO - Cooperativa Agrícola de Campo Mourão - PR, Doutorando UEM.

${ }^{3}$ Prof. Adjunto, Curso de Mestrado em Engenharia Agrícola, UNIOESTE, e-mail: ssouza@unioeste.br.

${ }^{4}$ Engo Agrícola, M.Sc., Doutorando UEM.

Recebido pelo Conselho Editorial em: 14-1-2002

Aprovado pelo Conselho Editorial em: 29-9-2004
} 


\section{INTRODUÇÃO}

Muitas propriedades e comunidades rurais no Brasil, principalmente nas regiões Norte e Nordeste, não são atendidas com energia elétrica, pois estão distantes das centrais de geração de eletricidade. Uma das formas de garantir o suprimento de energia elétrica nessas propriedades ou comunidades rurais isoladas seria a implantação de sistemas energéticos baseados em fontes alternativas de energia. Dentre elas, a energia solar é uma das mais promissoras, podendo ser utilizada no aquecimento de água por meio dos coletores termossolares e geração de eletricidade por meio de painéis fotovoltaicos para iluminação e bombeamento de água.

O dispositivo conversor da energia solar em eletricidade é a chamada célula fotovoltaica, e a associação dessas células compõe os chamados painéis fotovoltaicos. A maior ou menor capacidade de geração de energia utilizando-se de painel fotovoltaico depende do arranjo dos painéis, em série ou paralelo, e da radiação solar local, a qual tem influência direta na corrente elétrica (ALMEIDA et al., 1999). Tal sistema pode ser acoplado diretamente a um motor elétrico e bomba centrífuga ou de diafragma para bombeamento de água nos momentos em que ocorre a disponibilidade de energia solar.

Para LOXSOM \& DURONGKAVEROJ (1994), um sistema fotovoltaico de bombeamento diretamente acoplado é constituído de três componentes principais: um conjunto fotovoltaico, um motor de corrente contínua e uma bomba d'água. O painel fotovoltaico converte energia solar em corrente elétrica que alimenta o motor, o qual é acoplado à bomba d'água. Quando o painel supre o motor com potência elétrica suficiente, ele produz torque mecânico e a bomba começa a trabalhar.

$\mathrm{O}$ rendimento e capacidade de bombeamento dos sistemas fotovoltaicos são particularmente dependentes de certas condições de trabalho. Conforme SILVA (2000), a radiação solar aplicada sobre o módulo gera energia elétrica para o bombeamento de água, e a vazão bombeada mantém relação com a altura manométrica e capacidade de geração dos módulos fotovoltaicos.

THOMAS (1987) esclarece que as bombas de diafragma e de pistão são as mais adaptadas e recomendadas aos sistemas fotovoltaicos diretamente acoplados, porque a produção independe da carga, sendo diretamente proporcional ao volume varrido pelo diafragma ou pelo pistão e por responderem melhor às variações de potência provocadas pela irradiância solar.

KOU et al. (1998), utilizando-se de um sistema SIEMENS M75 composto de dez módulos e uma bomba SCS 5.7-160, operando na combinação de seis módulos em série e quatro em paralelo, observaram que o sistema exigiu $300 \mathrm{~W} \mathrm{~m}^{-2}$ para acionamento da motobomba de diafragma e que a vazão fornecida aumentava com a irradiância e diminuía com a carga. A máxima vazão verificada no estudo foi de $2,2 \mathrm{~L} \mathrm{~s}^{-1}$, livre de carga, e a máxima altura manométrica vencida pelo sistema foi de $25 \mathrm{~m}$ com vazão de $0,5 \mathrm{~L} \mathrm{~s}^{-1}$.

Apesar de as motobombas de diafragma serem as mais adaptadas à aplicação direta em sistemas fotovoltaicos, ainda são raros os estudos relacionados ao seu comportamento operacional nessa condição de aplicação. PROTOGEROPOULOS \& PEARCE (2000) observaram o comportamento de uma motobomba SHURFLO 9325 de diafragma, operando a 12 e $24 \mathrm{~V}$, acionada por módulos fotovoltaicos de diferentes potências. Nas condições de $12 \mathrm{~V}$, a máxima vazão observada foi, aproximadamente, de $370 \mathrm{~L} \mathrm{~h}^{-1}$ a uma altura manométrica de $5 \mathrm{~m}$. Sob as mesmas condições, verificou-se que os módulos de 110 e $165 \mathrm{Wp}$ de potência não provocaram variações de vazão quando a irradiância alcançava $700 \mathrm{~W} \mathrm{~m}^{-2}$. A eficiência hidráulica chegou próxima de $60 \%$ nas condições de 20 e $40 \mathrm{~m}$ de altura manométrica. Para a situação de operação em $24 \mathrm{~V}$ e $5 \mathrm{~m}$ de altura manométrica, a vazão instantânea ficou em torno de $500 \mathrm{~L} \mathrm{~h}^{-1}$, com $110 \mathrm{Wp}$ de potência e irradiância entre 700 e $1.000 \mathrm{~W} \mathrm{~m}^{-2}$. A máxima eficiência hidráulica observada para tal tensão foi de $50 \%$ para altura manométrica de 40 a $50 \mathrm{~m}$. 
A vazão de um sistema fotovoltaico de bombeamento diretamente acoplado depende de certas condições de funcionamento. Baseado nisso, JAFAR (2000) analisou o comportamento de um desses sistemas (não especificado), operando em cinco alturas manométricas, variando de 2,9 a 13,8 m, com o objetivo de modelar o fluxo de água fornecido, concluindo que a vazão depende basicamente de dois fatores: da carga de bombeamento e da irradiância solar e que, em geral, a vazão aumenta com a irradiância solar, mas não linearmente. Concluiu-se, também, que a equação de segunda ordem ajustase bem aos dados de vazão em relação à irradiância, porém, devido às inúmeras possibilidades de cargas de bombeamento, as equações são vinculadas a cada carga de trabalho.

Neste trabalho, teve-se o objetivo de obter informações quanto ao comportamento dos parâmetros operacionais de um sistema fotovoltaico de bombeamento de água, tais como: eficiência energética global e vazão de água, submetendo-o a diferentes alturas manométricas e níveis de irradiância solar e, finalmente, estabelecer um modelo para estimativa de vazão de água do sistema em função da altura manométrica e irradiância. O sistema foi composto de uma moto-bomba SHURFLO modelo 2088, acionada por um painel fotovoltaico SOLARIS modelo Ap6150. Tal observação visou intensificar os estudos aplicados a esses sistemas e dar respaldo a um dimensionamento mais adequado às necessidades comuns de operação.

\section{MATERIAL E MÉTODOS}

O trabalho foi realizado na UNIOESTE - Universidade Estadual do Oeste do Paraná - Câmpus de Cascavel - PR, a uma latitude de 24 $53^{\circ}$ ' sul, longitude de $53^{\circ} 23^{\prime}$ oeste e altitude média de $682 \mathrm{~m}$.

A análise foi feita mediante montagem de uma bancada de testes, junto à Estação Agrometeorológica e Laboratório de Hidráulica do referido Câmpus, composta por duas caixas d'água em diferentes níveis. O sistema de bombeamento foi composto por uma moto-bomba SHURFLO modelo 2088, acionada por um painel fotovoltaico SOLARIS modelo Ap6150.

A metodologia empregada na análise de sistemas fotovoltaicos de bombeamento de água foi vinculada à determinação da vazão, altura manométrica, tensão e corrente do motor e irradiância global no plano do painel. Dessa forma, fez-se necessário a montagem de uma bancada de ensaios, a qual permitiu submeter o sistema a diferentes condições de trabalho.

O experimento foi composto de duas caixas d'água de $250 \mathrm{~L}$ em diferentes níveis. A motobomba acionada pela potência do painel solar fotovoltaico foi montada em uma bancada sobre a caixa inferior e acoplado um manômetro diferencial de mercúrio entre a tubulação de sucção e recalque, o qual permitiu, por meio do deslocamento da coluna de mercúrio, a leitura da pressão de trabalho e, conseqüentemente, a altura manométrica. A tubulação de recalque foi composta por um registro de gaveta que permitiu variar a pressão no sistema, diferenciando, assim, a altura manométrica de trabalho, conforme metodologia de teste citada por LASNIER e ANG (1990). A caixa em nível superior recebia o volume de água bombeado e, munida de um "ladrão" (sistema de descarga), permitia o retorno da água à caixa em nível inferior que, por sua vez, alimentava novamente o sistema, mantendo constante o volume de água da caixa e fechando o ciclo de trabalho. Na Figura 1, apresentase a montagem do experimento.

As diferentes alturas manométricas estudadas, num total de seis, foram determinadas por meio de testes preliminares, buscando equivalência com as cargas do catálogo da moto-bomba, respeitando os limites da bancada de testes. Seguindo a observação, as alturas manométricas empregadas foram de $4 ; 7,5 ; 11 ; 13 ; 15$ e 19 m. Por meio de uma prévia calibração, os pontos equivalentes a cada altura manométrica em análise foram referenciados no manômetro, os quais no momento da tomada de dados eram alcançados com o registro de gaveta. 


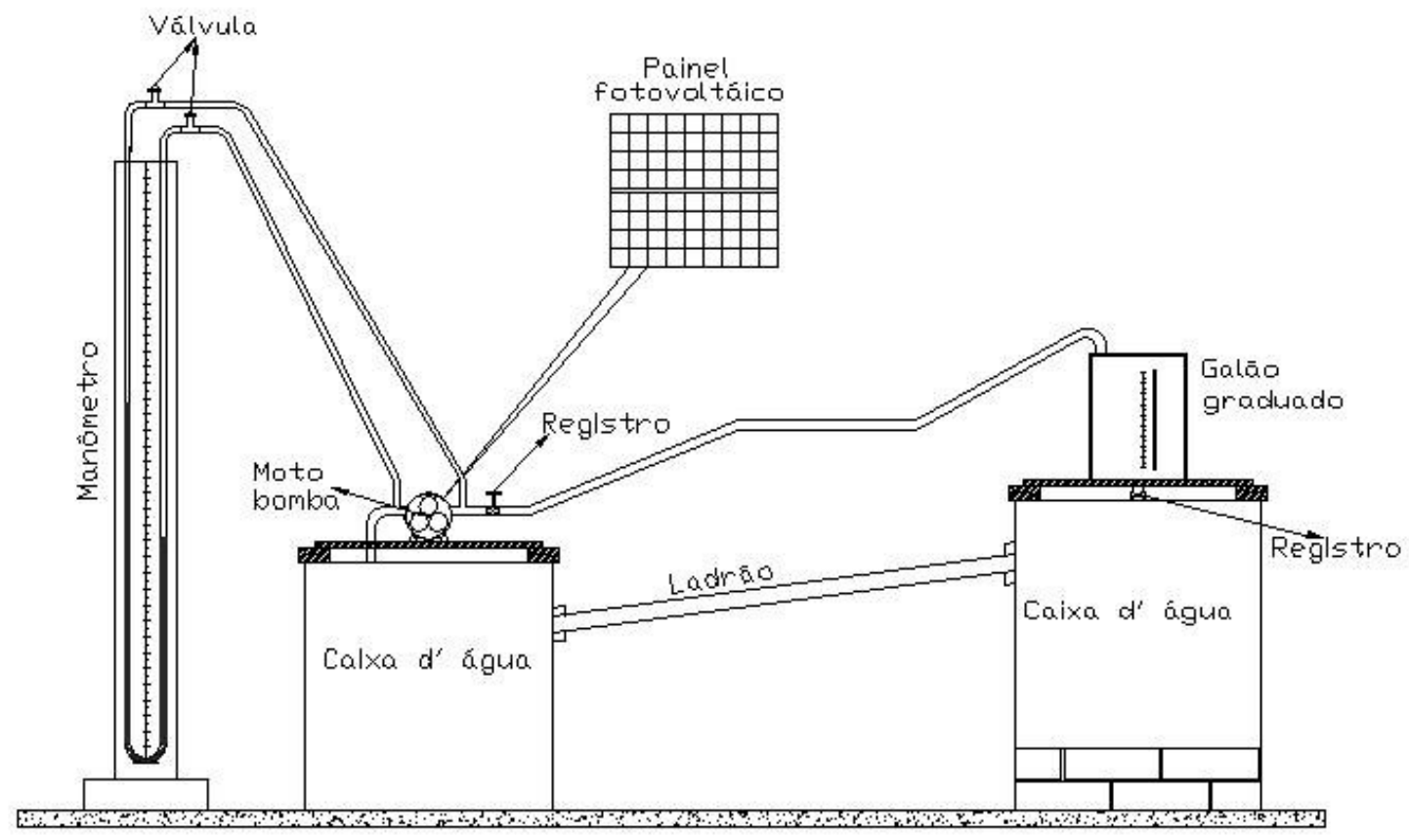

FIGURA 1. Diagrama esquemático do experimento.

O nível de irradiância solar aplicada ao painel para conversão em potência elétrica, em cada situação e instante de trabalho, foi fornecido pela Estação Agrometeorológica, obtido por um Piranômetro KIPP \& ZONEN, modelo CM3, e um sistema de aquisição de dados Micrologger CAMPBELL SCIENTIFIC-INC, modelo CR10x. A potência gerada pelo painel e aplicada à motobomba foi determinada por meio da tensão e corrente fornecidas pelo painel à motobomba, com auxílio de um voltímetro digital MINIPA, modelo ET-2060, e um amperímetro digital BRYMEN, modelo BM600. A potência hidráulica $(\mathrm{kW})$ oferecida pela motobomba foi calculada segundo PROTOGEROPOULOS \& PEARCE (2000), baseando-se no peso específico da água na carga de bombeamento e na vazão fornecida pela motobomba.

A eficiência do painel foi obtida pela relação entre a potência elétrica gerada e a potência de irradiância solar disponível (irradiância solar $\mathrm{W} \mathrm{m}^{-2}$ multiplicada pela área do painel, 1,26 $\mathrm{m}^{2}$ ). A eficiência da motobomba foi definida pela relação entre a potência hidráulica e a potência elétrica gerada, e a eficiência global do sistema, pela relação da potência hidráulica e a energia solar disponível.

\section{RESULTADOS E DISCUSSÃO}

\section{Comportamento da eficiência do sistema}

Os resultados encontrados permitiram verificar que, para menores alturas manométricas, obtiveram-se maiores vazões, porém não representam a maior eficiência do conjunto. O sistema é mais eficiente quando submetido a cargas mais elevadas, visto que sua eficiência é função da potência hidráulica que aumenta de forma proporcional ao aumento da carga (altura manométrica). Na condição de $19 \mathrm{~m}$ de altura manométrica (Figura 2b), verificou-se a maior eficiência da motobomba de 39\%, e a máxima eficiência global do conjunto de 2,3\%. A eficiência global do sistema é baixa devido à baixa eficiência de conversão do painel. A máxima eficiência do painel foi de $8 \%$ para a altura manométrica de $4 \mathrm{~m}$ (Figura 2a), em que se verificou também a máxima vazão fornecida pelo sistema. 


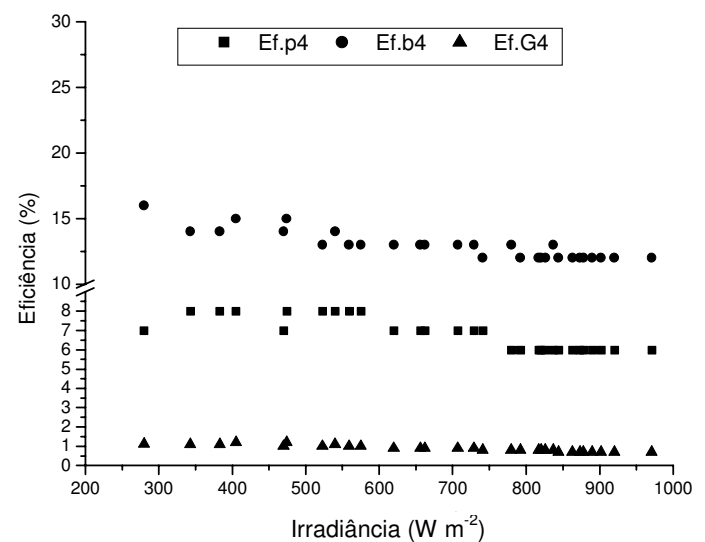

(a)

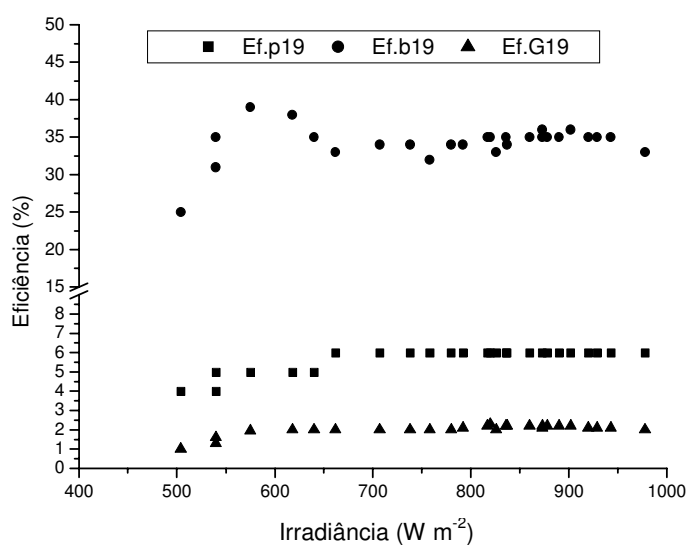

(b)

*(Ef.p - Eficiência do painel, Ef.b - Eficiência da motobomba, Ef.G - Eficiência global).

FIGURA 2. Comportamento da eficiência do sistema em relação à irradiância solar disponível: (a) altura manométrica de $4 \mathrm{~m}$ e (b) altura manométrica de $19 \mathrm{~m}$.

A eficiência global é influenciada principalmente pelo comportamento da motobomba do sistema, cuja eficiência e variação são mais significativas que no caso do painel fotovoltaico do conjunto. De uma forma geral, o aumento da eficiência global com a irradiância é crescente (até $600 \mathrm{~W} \mathrm{~m}^{-2}$ ) e depois decrescente. Isso se explica pelo fato de que a potência hidráulica é limitada e a irradiância solar disponível não o é, assim haverá um determinado ponto em que esse limite ocorre para um potencial de irradiância solar maior, ocasionando a diminuição da eficiência global.

\section{Capacidade de bombeamento do sistema para diferentes alturas manométricas}

Na Figura 3, apresentam-se os gráficos referentes ao comportamento da vazão fornecida e potência empregada na motobomba com relação à irradiância solar disponível. Observou-se que a melhor utilização da potência elétrica gerada pelo painel fotovoltáico foi obtida a uma carga de $11 \mathrm{~m}$, alcançando $74 \mathrm{~W}$ dos $75 \mathrm{~W}$ que o painel pode fornecer segundo o fabricante (Figura 3c).

Analisando-se a capacidade de bombeamento de água do sistema, nas diferentes condições de altura manométrica (Tabela 1), observa-se que o nível médio de irradiância variou entre as cargas, devido a começarem e finalizarem sua operação em níveis diferentes de irradiância. A vazão, como esperado, diminuiu com a carga, porém exigiu que mais energia fosse disponibilizada para operação.

O número de horas de operação também variou com a carga e, como é conhecido apesar de não tão bruscamente, também com o dia, justificando a determinação dos níveis de irradiância inicial e final de operação, por meio dos quais se pode determinar o número de horas de funcionamento do sistema. Quando sujeito a cargas maiores, o sistema operou menor tempo em um mesmo dia, visto que são exigidos níveis maiores de irradiância, o que, conseqüentemente, afeta o volume total de água bombeado durante o dia. Para as condições de melhor desempenho do sistema, com vazão média de $5.565 \mathrm{~L} \mathrm{dia}^{-1}$ a $4 \mathrm{~m}$, seria possível alcançar $2.031,0 \mathrm{~m}^{3}$ de água bombeada por ano. 

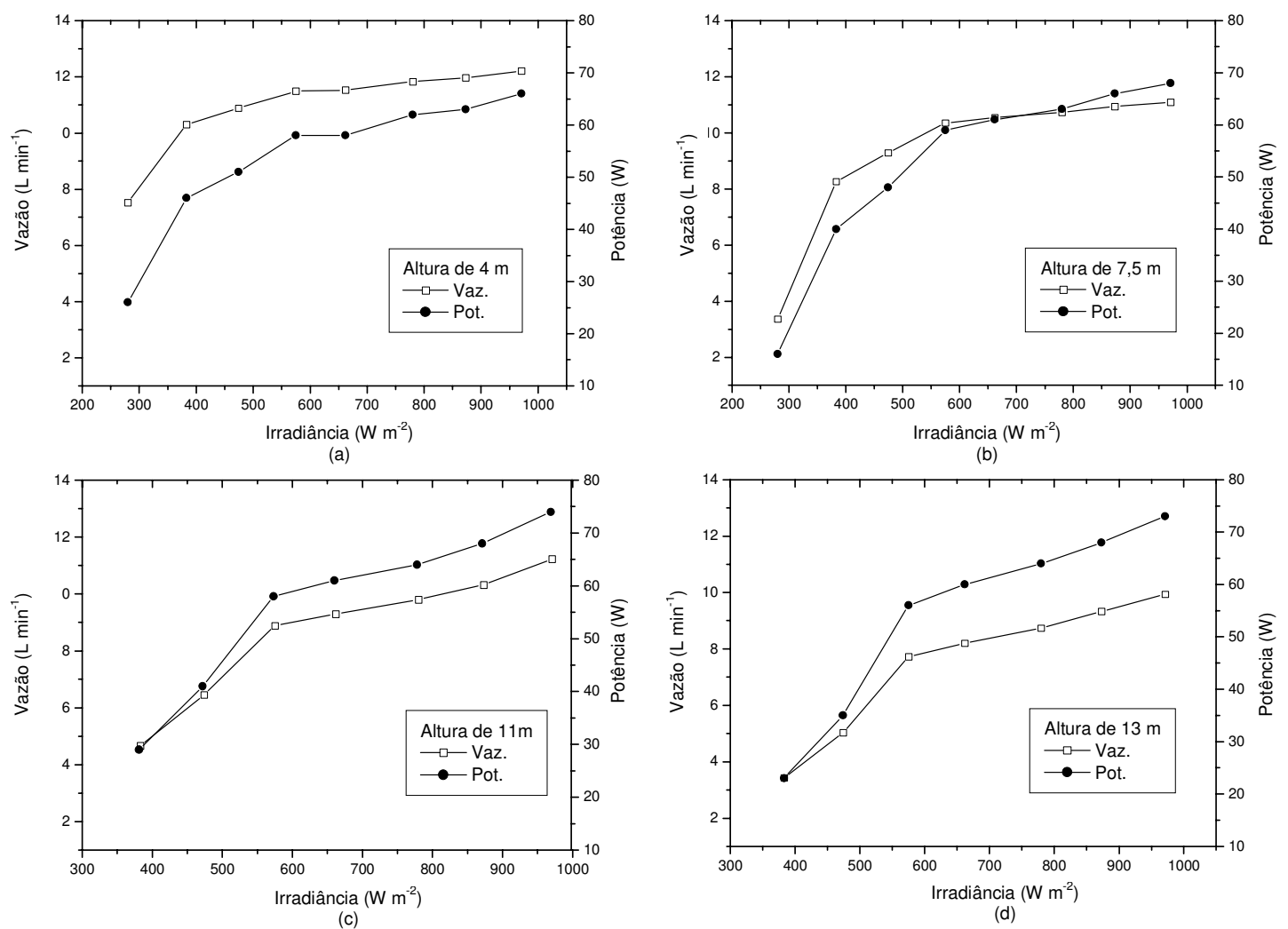

FIGURA 3. Comportamento da potência elétrica gerada e vazão fornecida pelo sistema em relação à irradiância disponível.

TABELA 1. Vazão média fornecida pelo sistema em diferentes cargas de bombeamento.

\begin{tabular}{ccccc}
\hline $\begin{array}{c}\text { Carga } \\
(\mathrm{m})\end{array}$ & $\begin{array}{c}\text { Irradiação Média } \\
\left(\mathrm{W} \mathrm{m} \mathrm{m}^{-2}\right)\end{array}$ & $\begin{array}{c}\text { Vazão Média } \\
\left(\mathrm{L} \mathrm{min}^{-1}\right)\end{array}$ & $\begin{array}{c}\text { Horas de Operação } \\
(\text { horas })\end{array}$ & $\begin{array}{c}\text { Vazão Diária } \\
\left(\mathrm{L} \mathrm{dia}^{-1}\right)\end{array}$ \\
\hline 4 & 685 & 10,91 & 8,50 & 5.565 \\
7,5 & 717 & 9,89 & 8,25 & 4.941 \\
11 & 755 & 9,31 & 7,75 & 4.329 \\
13 & 769 & 8,36 & 7,50 & 3.761 \\
15 & 784 & 8,15 & 7,00 & 3.425 \\
19 & 809 & 6,52 & 6,25 & 2.445 \\
\hline
\end{tabular}

\section{Modelo de estimativa de vazão}

A vazão de um sistema fotovoltaico de bombeamento diretamente acoplado depende, basicamente, do nível de irradiância solar e da carga de bombeamento (altura manométrica), ou seja, a vazão é função da irradiância e da carga $(\mathrm{Q}=\mathrm{f}(\mathrm{G}, \mathrm{H}))$, sendo que a vazão em relação à irradiância solar não apresenta uma linearidade definida. Dessa forma, analisando-se a regressão de melhor ajuste dos dados experimentais da Tabela 1 e Figura 3, obteve-se uma função quadrática ou polinomial de segunda ordem, como a mais ajustável, convergindo com o modelo de comparação.

Um modelo polinomial de terceira ordem também poderia ser utilizado, porém não representa diferença significativa na estimativa da vazão e, contudo, torna o modelo baseado na metodologia de JAFAR (2000) mais complexo. Dessa forma, de acordo com o ajuste encontrado, o modelo proposto 
pôde ser definido por um polinômio de segunda ordem, cujo produto da equação é função de três coeficientes, obtidos por:

$$
\mathrm{Q}=\mathrm{b}_{0}+\mathrm{b}_{1}(\mathrm{G})+\mathrm{b}_{2}\left(\mathrm{G}^{2}\right)
$$

em que,

$\mathrm{G}$ - irradiância solar, $\mathrm{W} \mathrm{m}^{-2}$, e

$b_{0}, b_{1}$ e $b_{2}$ - coeficientes da equação.

Os coeficientes $b_{0}, b_{1}$ e $b_{2}$, devido às diferentes cargas de bombeamento, são restritos a cada situação, o que leva a entender que dependem da altura manométrica. Na Tabela 2, apresentam-se as equações ajustadas.

TABELA 2. Equações ajustadas para cada carga em função da irradiância solar

\begin{tabular}{ccc}
\hline Carga $(\mathrm{m})$ & Equações de melhor ajuste & $\left(\mathrm{r}^{2}\right)$ \\
\hline 4 & $\mathrm{Q}=0,1057+0,0291 \mathrm{G}-2 \times 10^{-5} \mathrm{G}^{2}$ & 0,96 \\
7,5 & $\mathrm{Q}=-8,8346+0,0505 \mathrm{G}-3 \times 10^{-5} \mathrm{G}^{2}$ & 0,97 \\
11 & $\mathrm{Q}=-8,0428+0,0379 \mathrm{G}-2 \times 10^{-5} \mathrm{G}^{2}$ & 0,97 \\
13 & $\mathrm{Q}=-6,1755+0,0297 \mathrm{G}-1 \times 10^{-5} \mathrm{G}^{2}$ & 0,98 \\
\hline
\end{tabular}

As cargas de 15 e $19 \mathrm{~m}$ submeteram os coeficientes do modelo estudado às situações pouco ajustáveis, gerando erros conseqüentes na estimativa, ou seja, não são passíveis de boa estimativa de vazão por esse modelo.

O comportamento da vazão real e estimada pelo modelo pode ser visualizado na Figura 4. Como se observa, o modelo inicia subestimando a capacidade de bombeamento do sistema e, com o aumento da altura manométrica, o comportamento é invertido, de forma a superestimar a vazão. Conclui-se também que o modelo é mais adequado às condições de até $11 \mathrm{~m}$ de carga de bombeamento, em que descreve um comportamento bem similar à situação real.

Outra observação obtida é que o modelo é adequado para o total de casos até um nível aproximado de $700 \mathrm{~W} \mathrm{~m}^{-2}$, a partir do qual os valores gerados começam a distanciar-se dos valores reais obtidos no experimento.

O modelo apresenta um desvio, calculado por meio do erro médio, variando de $3,4 \%$ a $13 \%$ para alturas manométricas de até $11 \mathrm{~m}$ e $18,8 \%$ para $13 \mathrm{~m}$, que representa um desvio médio na ordem de $7,5 \%$ até $11 \mathrm{~m}$ e 13,2\% para o total de cargas, o que reforça a afirmação de o modelo ser mais apropriado às condições de até $11 \mathrm{~m}$ de altura. O desvio encontrado por JAFAR (2000), em estudo similar, foi da ordem de $8 \%$, relativamente mais próximo aos dados reais, apesar de apresentar ajuste menos significativo. 

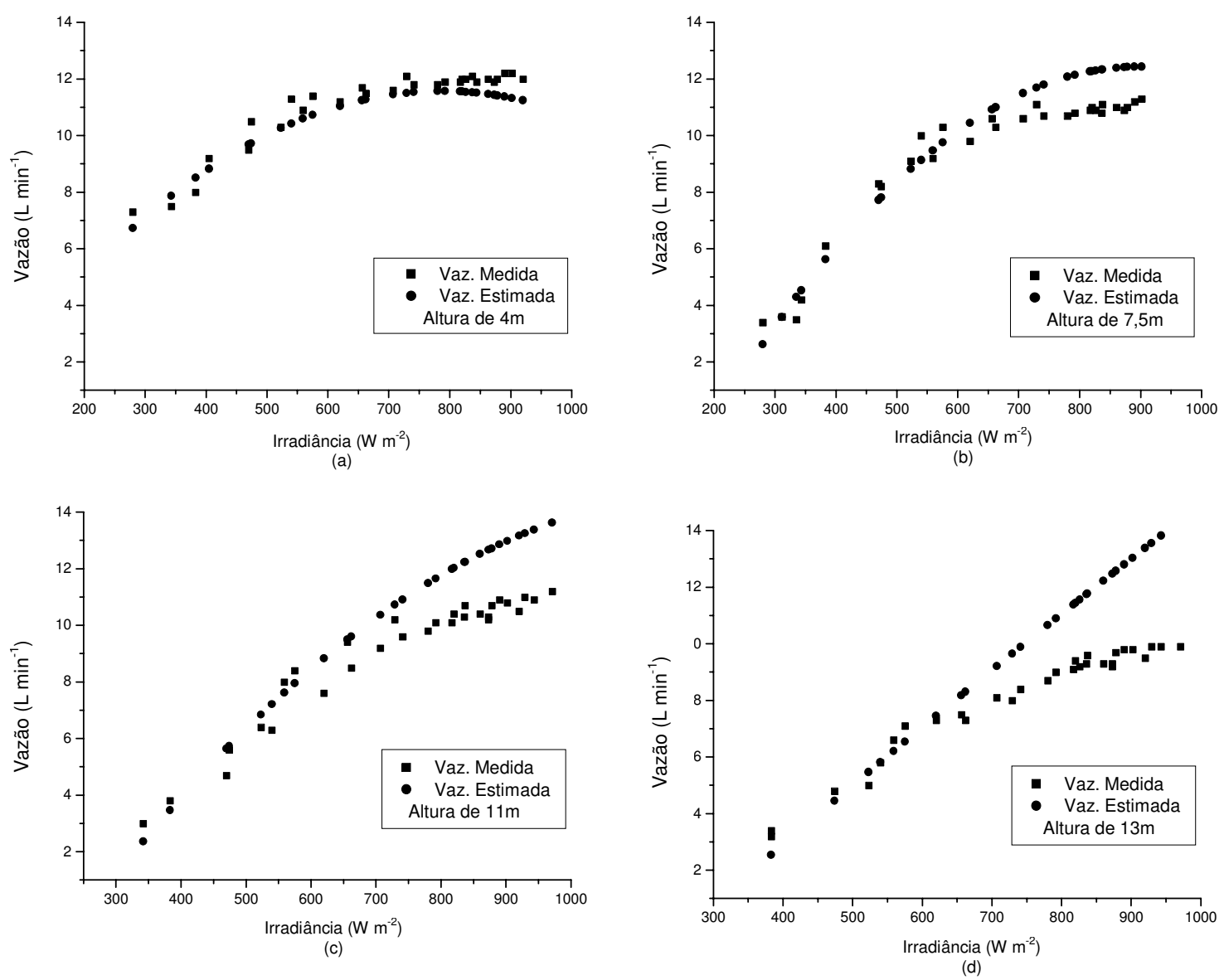

FIGURA 4. Comparação entre a vazão medida e a estimada pelo modelo.

\section{CONCLUSÕES}

A máxima eficiência obtida para o painel fotovoltaico foi de $8 \%$ para uma carga de bombeamento de $4 \mathrm{~m}$.

A motobomba apresentou uma eficiência máxima de 39\%, e o sistema alcançou a eficiência global máxima de 2,3\%, ambos nas condições de maior carga, no caso $19 \mathrm{~m}$.

O melhor potencial de exploração de potência do painel foi verificado para a carga de bombeamento de $11 \mathrm{~m}$, com $74 \mathrm{~W}$.

O sistema pode fornecer uma vazão média de 6,52 a 10,91 $\mathrm{L} \mathrm{min}^{-1}$ de água ou, ainda, de 2.445 a $5.565 \mathrm{~L} \mathrm{dia}^{-1}$, que será função do nível de irradiância solar disponível e da carga de bombeamento empregada no sistema.

O modelo de estimativa de vazão teve melhor ajuste para alturas manométricas até $11 \mathrm{~m}$.

\section{REFERÊNCIAS}

ALMEIDA, L.M.G.; PERDIGÃO, M.S.D.; FRANCISCO, N.M.T. Painéis solares activos. Trabalho final de Mecatrónica. 1999. Disponível em: <http://alumni.dee.uc.pt/ torrao/rel/final/Psolar.html> Acesso em: 7 fev. 2001.

JAFAR, M. A model for small-scale photovoltaic solar water pumping. Renewable Energy, Oxford, v.69, n.1-2, p.85-90, 2000. 
KOU, Q.; KLEIN, S.A.; BECKMAN, W.A. A method for estimating the long-term performance of direct-coupled pv pumping systems. Solar Energy, Oxford, v.64, n.1-3, p.33-40, 1998.

LASNIER, F.; ANG, T.G. Photovoltaic engineering handbook. New York: IOP Publishing, 1990. $548 \mathrm{p}$.

LOXSOM, F.; DURONGKAVEROJ, P. Estimating the performance of a photovoltaic pumping system. Solar Energy, Oxford, v.52, n.2, p.215-19, 1994.

PROTOGEROPOULOS, C.; PEARCE, S. Laboratory evaluation and system sixing charts for a 'second generation' diretct PV-powered, low cost submersible solar pump. Solar Energy, Osxford, v.68, n.5, p.453-74,2000.

SILVA, C.D. Potência gerada e eficiência dos módulos fotovoltaicos em função da radiação global incidente para bombeamento de água. In: SEMINÁRIO DE ENERGIA NA AGRICULTURA, 1., 2000, Uberaba. Anais... Uberaba: Fazenda Energética, 2000. p.92-7.

THOMAS, M.G. Water pumping: the solar alternative. Center Photovoltaic Systems Design. [S.L.:s.n.],1987. 67 p. 